\title{
Uncertainties of precipitation products and their impacts on runoff estimates through hydrological land surface simulation in Southeast Asia
}

\author{
Shunji Kotsuki ${ }^{1}$ and Kenji Tanaka ${ }^{2}$ \\ ${ }^{1}$ Graduate School of Engineering, Kyoto University, Japan \\ ${ }^{2}$ Disaster Prevention Research Institute, Kyoto University, Japan
}

\begin{abstract}
:
Precipitation is one of the most important climate variables for runoff simulation. The main objective of this study is to reveal uncertainties in precipitation products and demonstrate how those uncertainties affect runoff estimations in Southeast Asia. Through comparing precipitation products and performing hydrological simulations, the authors have reached the following main conclusions. In Southeast Asia, gauge-based precipitation products have similar monthly precipitation patterns and small differences in precipitation amount, except for Myanmar and Sumatra Island where few gauging stations are used for the precipitation products. Conversely, the uncertainties in seasonal and annual precipitation are large in Southeast Asia if few gauging stations are used for the precipitation products. Since most of the difference in precipitation translates to difference in runoff in wet region, small errors in precipitation can easily result in large errors in runoff in Southeast Asia. Even if located in wet Southeast Asia, impacts of precipitation errors on runoff estimates are different depending on precipitation amount and runoff ratio. In Chao Phraya Basin, relatively low precipitation and runoff ratio cause large percentage differences in simulated runoff. In Irrawaddy Basin, relatively high precipitation and runoff ratio cause large difference in simulated runoff volume.
\end{abstract}

KEYWORDS precipitation; water balance; hydrological land surface simulation; Southeast Asia; uncertainty

\section{INTRODUCTION}

Intermittent heavy rain from June 2011 led to massive flooding in the Chao Phraya River Basin, Thailand. The World Bank (2012) estimated that the total economic damage and losses from the floods as of December 1, 2011, stands at 1,425 trillion Baht (45.7 billion USD). The damage has affected not only Thailand but also industries in other countries such as Japan, as widely reported in the press. After the massive flooding in 2011, the Thai government intends to revise their master plan (prepared in 1999) for management of the entire river basin. For long-term management of the water resources, it is necessary to know the exact amount of runoff from the basins. Hydrological modeling is one tool to estimate the amount of runoff using meteorological forcing and geophysical data. Simulated runoff using a hydrological model, however, always includes uncertainties. Meteorological forcing data, which is represented by precipitation, temperature and radiation, has uncertainties in data error itself and interpolation processes. Precipitation is one of the most important climate variables for runoff simulation since it is the predominant and ultimate source of water for the land surface water budget (Fekete and Vorosmarty, 2004). This paper will focus on uncertainties in precipitation products and their impacts on runoff estimates.

Precipitation products have to be used for hydrological simulations in large basins when surface gauging data is insufficient. A number of gauge-based precipitation products have been published and can be classified into three types. The first type of product is produced based on gauged precipitation on the land surface. The Global Precipitation Climatology Centre (GPCC; Rudolf et al., 2010) and APHRODITE (Yatagai et al., 2012) are representative products of this type. The second type of product is produced using satellite observation data such as the Global Satellite Mapping of Precipitation (GSMaP; Ushio et al., 2009). The third type of product is derived from satellite and surface measurements, which are represented by the Global Precipitation Climatology Project (GPCP; Huffman et al., 2013). Supplement Figure S1-a shows the mean annual precipitation of the four products from 1998 to 2006. While the spatial distributions of precipitation coincide with each other, there are differences in the amount of precipitation. It is important to understand the accuracy of a product, the difference between precipitation products, and the impact that these differences in the amount of precipitation have on simulated runoff. Yatagai et al. (2012) reported that the APHRODITE underestimates precipitation compared to the GPCC in most Eurasian areas. They concluded the underestimation may be caused by different quality control systems and interpolation methods. Through global analyses using seven precipitation products, Biemans et al. (2009) pointed out that the representation of seasonality is similar in precipitation products, but the uncertainty in mean annual precipitation is large, especially in mountainous, arctic, and small basins. Getirana et al. (2011) mentioned that gaugebased products are still the most representative of the actual precipitation in the northern Amazon Basin. Fekete and Vorosmarty (2004) pointed out that in wet region, where the precipitation always exceeds the potential evaporation, any error in the precipitation translates to approximately the same absolute error in runoff (which will result in higher relative error since runoff is always less than the precipitation).

This paper describes a comparative study of precipitation

Correspondence to: Shunji Kotsuki, Water Resources Research Center, DPRI, Kyoto University, Gokasho, Uji, Kyoto 611-0011, Japan. E-mail: kotsuki.water@gmail.com C2013, Japan Society of Hydrology and Water Resources. 
products through hydrological land surface simulations in Southeast Asia. In the global analyses performed by Fekete and Vorosmarty (2004) and Biemans et al. (2009), the whole of Southeast Asia is treated as a wet region. The main objective of this study is to confirm whether their conclusions are applicable or not in Southeast Asia. Additionally, detailed consideration is given for Chao Phraya, Mekong, and Irrawaddy Basins. Those basins have many challenges related to flood control and water resources management.

\section{METHODOLOGY}

\section{Precipitation data}

Four precipitation data sets were used to produce simulations for discussion: GPCC_full version 6.0 (hereafter GPCC), APHRODITE version 1101 (hereafter APHRO), GPCP 1DD version 1.2 (hereafter GPCP), and GSMaP_MWR version 4.8.4 (hereafter GSMaP). Precipitation data from gauged records (hereafter K12) was available only for the Chao Phraya River Basin. Precipitation records were provided by the Royal Irrigation Department (RID) and the Thai Meteorological Department (TMD) through two projects: IMPAC-T and GAME-T2 Data Center (GAME-T2). The spatial and temporal resolutions of the precipitation data are shown in Supplement Table SI. The number of rain gauging stations per $1000 \mathrm{~km}^{2}$, calculated by dividing the number of stations in the target basin by the basin area, used for K12, APHRO, and GPCC in the Chao Phraya, Mekong, and Irrawaddy Basins, are shown in Supplement Table SI. Elevation and distributions of rain gauge stations used for GPCC and APHRO are shown in Figure 1.

\section{Hydrological model}

A long-term water-balance simulation was conducted using a hydrological land-surface model. The land-surface process calculates the energy, radiation, and water budgets on the land surface with seven meteorological forcings: temperature, specific humidity, short-wave radiation, longwave radiation, atmospheric pressure, wind speed, and precipitation. In this study, the Simple Biosphere model including Urban Canopy (SiBUC; Tanaka, 2004) was used to calculate the land-surface process. The model was

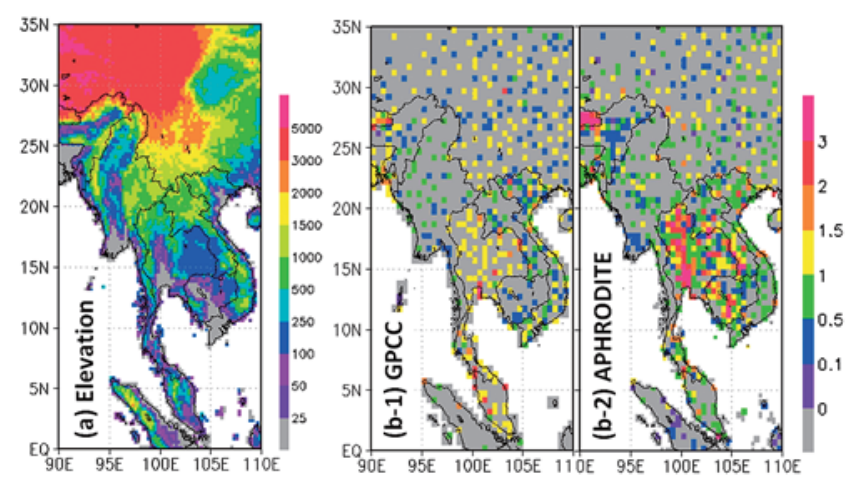

Figure 1. (a) Elevation of Southeast Asia (m) and the number of rain gauge stations per $30 \mathrm{~min}$ grid used for (b-1) GPCC and (b-2) APHRODITE developed from the Simple Biosphere ( $\mathrm{SiB}$ ) model (Sellers et al., 1986). Differences in land cover have a strong effect on energy, radiation, and water budget. SiBUC uses the mosaic approach to reflect land-cover mixtures. Because all model parameters can be determined with land-surface products, the model basically requires no parameter calibration.

\section{Study basins}

The hydrological simulations were conducted at a 0.25-degree spatial resolution for the Mekong River upper Mukdahan station and the Irrawaddy River upper Sagaing station. River discharge records for the two stations were obtained from the Global Runoff Discharge Centre (GRDC). The simulation was conducted at a 5 -min spatial resolution for the Chao Phraya River upper Nakhon Sawan station. River discharge records of the station were collected through the IMPAC-T project. Because large dams have impacts on river discharge, such effects were removed from the river discharge at Nakhon Sawan using the inflow, release, and pumped discharge of the Bhumibol and Sirikit Dams, with the following equation:

$$
E R_{C 2}=O R_{C 2}+[\text { Inf }+ \text { Pump }-O u f]_{B B, S K}
$$

where $E R$ is the runoff excluding dams effects $\left[\mathrm{m}^{3} \mathrm{~s}^{-1}\right], O R$ is the observed runoff $\left[\mathrm{m}^{3} \mathrm{~s}^{-1}\right]$, Inf is the inflow runoff at the dams $\left[\mathrm{m}^{3} \mathrm{~s}^{-1}\right]$, Pump is the water pumped into the dams $\left[\mathrm{m}^{3} \mathrm{~s}^{-1}\right]$, and Ouf is the discharge released from the dams $\left[\mathrm{m}^{3} \mathrm{~s}^{-1}\right]$. Subscripted $B B$ and $S K$ are the Bhumibol and Sirikit Dams, respectively. Subscripted $C 2$ means runoff in Nakhon Sawan (C.2 station) catchment. The released discharge includes water released from spillways and irrigation gates. The dam data were provided by the Electricity Generating Authority of Thailand (EGAT). Dam effects of the river discharge in Mekong and Irrawaddy Rivers were not removed because the authors do not have the reservoir operation data for the two basins.

\section{Other data sets}

Short-wave radiation (daily), long-wave radiation (3 hourly), specific humidity (daily), and temperature ( 3 hourly) data were recorded with a H08 data logger (Hirabayashi et al., 2008). Wind speed (6 hourly) and atmospheric pressure (6 hourly) were determined from reanalyzed data (Onogi et al., 2007). The forcing data, including precipitation, were downscaled for model mesh size using an interpolating method. The monthly precipitation from GPCC was disaggregated into daily values using daily H08 precipitation data. In the Eurasia region, APHRO's daily precipitation was used for the $\mathrm{H} 08$ daily precipitation data considering under-catch gauging bias caused by wind. Using the monthly diurnal variation of GSMaP-MWR averaged from 1998 to 2006, the daily precipitation from K12, GPCC, APHRO, and GPCP were disaggregated into hourly values. In other words, K12, GPCC, APHRO, and GPCP have the same monthly diurnal variation through the entire experimental period.

Different land-cover fractions were determined from GLCC ver2.0 provided by the US Geological Survey (USGS) and MIRCA 2000 (Portmann et al., 2010). Soil physical parameters were identified using Ecoclimap provided by Meteo-France. Drainage areas of the basins 
were produced using an upscaling algorithm (Yamazaki et al., 2009). The calculated catchment area of the basins agreed well with reported catchment areas. The river network in Southeast Asia and locations of the three stations are shown in Supplement Figure S1-b.

\section{RESULTS}

\section{Uncertainties of precipitation products}

Figure 2 shows correlations and root mean square errors (RMSEs) of monthly precipitation between GPCC and other products from 1998 to 2006 . Because seasonal water resources or floods in relatively large rivers like the targeting rivers are considered to be affected by monthly or seasonal precipitation amount, the correlations and RMSEs were calculated with monthly precipitations in this study. High correlations means similar monthly precipitation patterns, and low RMSEs means small differences in monthly precipitation amount, respectively.

High correlations are shown in Figure 2a-1 (between GPCC and APHRO) and 2a-2 (between GPCC and GPCP) in many regions, suggesting that those products have similar monthly precipitation patterns. However, low correlations are shown in Myanmar and Sumatra Island in Figure 2a-1 and 2a-2, where few gauging stations were used for APHRO and GPCC (Figure 1b-1 and 1b-2).

Low RMSEs are shown in Figure 2b-1 (between GPCC and APHRO) and 2b-2 (between GPCC and GPCP) except for Myanmar and Sumatra Island. On the other hand, monthly precipitation of GSMaP has lower correlations and higher RMSEs to GPCC than that of APHRO and GPCP.

\section{Long-term runoff simulation}

Annual runoff from 1979 to 2006 at the three stations is shown in Figure 3. Black bars, blue lines, purple lines, red lines, green lines, and orange lines represent observed river discharge and simulated runoff using GPCC, GPCP, K12, APHRO, and GSMaP, respectively. The calculated mean relative errors (MRE) and balance errors (BAL) in the three basins are shown in Supplement Table SII. MRE and BAL were calculated using the following equations:

$$
\begin{aligned}
& \text { MRE }=\frac{1}{N} \sum \frac{\left|V_{o b s}-V_{s i m}\right|}{V_{o b s}} \\
& B A L=\sum\left(V_{o b s}-V_{\text {sim }}\right) / \sum_{V_{o b s}}
\end{aligned}
$$

where, $V_{o b s}$ and $V_{\text {sim }}$ are the observed and simulated values, respectively. Precipitation errors were calculated between collected precipitation data (K12) and the four products. Runoff errors were calculated between simulated runoff using five sets of precipitation data and the observed discharge provided by RID and GRDC. The green, blue and gray colors represent very good $(\mathrm{MRE} \leq 0.1 ;|\mathrm{BAL}| \leq 15.0)$, $\operatorname{good}(0.1<\mathrm{MRE} \leq 0.3 ; 15.0<|\mathrm{BAL}| \leq 30.0)$, and poor
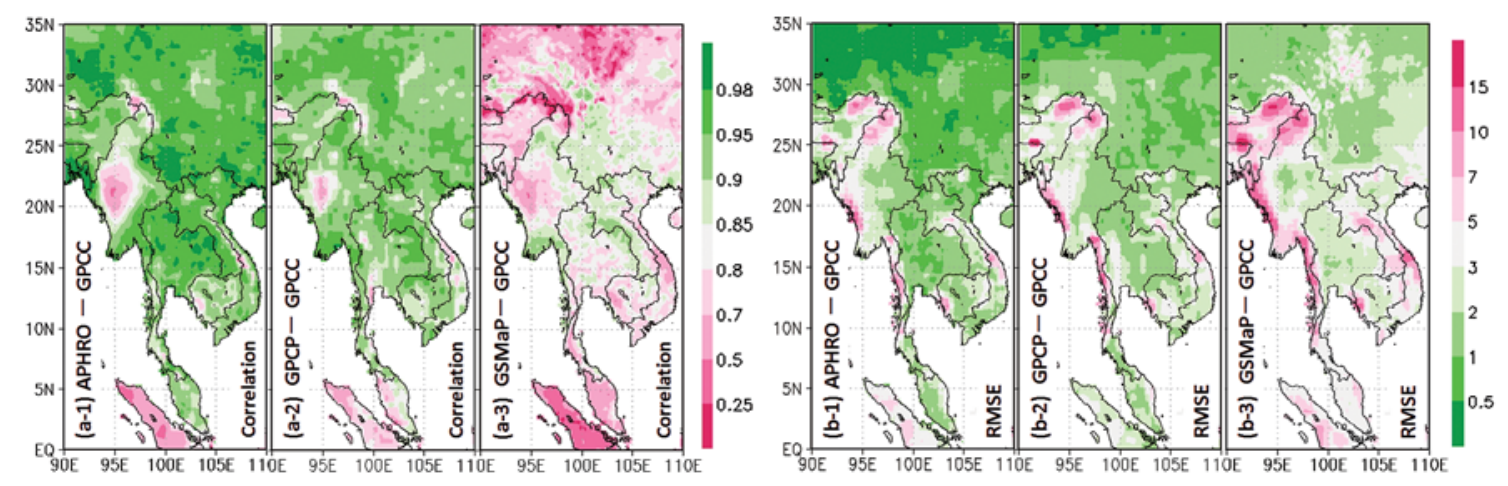

Figure 2. Correlations and root mean square errors (RMSEs, $\mathrm{mm}$ month ${ }^{-1}$ ) of monthly precipitation between products from 1998 to 2006. Correlation and RMSE between APHRODITE and GPCC are shown in a-1 and b-1. Correlation and RMSE between GPCP and GPCC are shown in a-2 and b-2. Correlation and RMSE between GSMaP and GPCC are shown in a-3 and $b-3$. Green color means high correlations and low RMSEs between products

(a) CHAO PHRAYA (NAKHON SAWAN)

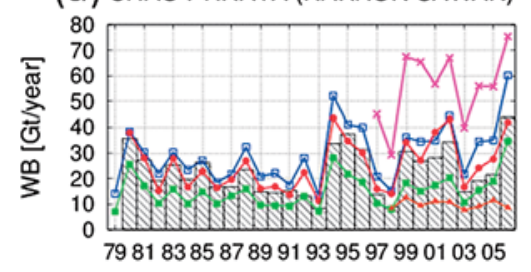

(b) MEKONG (MUKDAHAN)

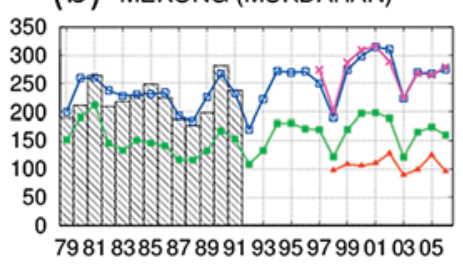

(c) IRRAWADDY (SAGAING)

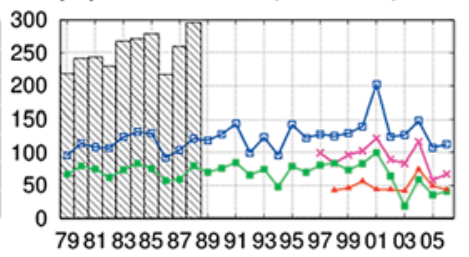

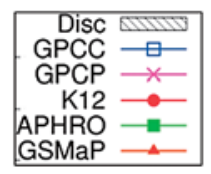

GSMaP

Figure 3. Annual runoff from 1979 to 2006 in the upper basin stations at (a) Nakhon Sawan in the Chao Phraya River, (b) Mukdahan in the Mekong River and (c) Sagaing in the Irrawaddy River. Black bars, blue lines, purple lines, red lines, green lines, and orange lines represent observed river discharge, simulated runoff using GPCC, GPCP, gauged precipitation (K12), APHRODITE, and GSMaP_MWR, respectively 
$(0.5<$ MRE; $40.0<|\mathrm{BAL}|)$ agreement with observed data, respectively.

$\mathrm{K} 12$ is considered to be the most accurate precipitation data in the Chao Phraya Basin because the number of rain gauging stations used for K12 was larger than that for GPCC and APHRO (Supplement Table SI). As shown in the comparison of annual precipitation (Supplement Table SII), GPCC agreed well with the K12 data. APHRO, GPCP, and GSMaP displayed an underestimation, overestimation, and a large underestimation, respectively, when compared with the K12 data. Of the five simulations, runoff using K12 showed the best agreement with observations, as shown in Figure $3 \mathrm{a}$ and Supplement Table SIIb. It should be noted that the simulation was conducted without any parameter calibration. This suggests that the SiBUC can reproduce annual runoff well in this basin when accurate precipitation records are used. Simulated runoff using GPCC and APHRO, which are gauge-based products, resulted in approximately $30 \%$ overestimation and underestimation, respectively.

In the Mekong Basin, simulated runoff using GPCC showed good agreement with observations (Figure $3 \mathrm{~b}$ and Supplement Table SIIc). Simulated runoff using GPCC and GPCP were almost the same after 1997, suggesting that a simulation using GPCP would show good agreement with observations when observed discharge become available after 1997. Simulated runoff using APHRO was lower than the observed data, suggestion that precipitation projections using APHRO was underestimated in the Mekong Basin.

In the Irrawaddy Basin, both simulations using GPCC and APHRO produced large underestimations. Underestimation of precipitation could be a possible reason for the large underestimation of runoff because a limited number of rain gauging stations was used for the Irrawaddy Basin. As shown in Figure 2, seasonal precipitation has large uncertainty in precipitation in Myanmar. Additional studies should be performed to determine the reason for the underestimation in the Irrawaddy Basin.

\section{DISCUSSION}

In Chao Phraya River, simulated runoffs using K12, GPCC and APHRO precipitation show good agreement with observation. In Mekong River, GPCC and GPCP can be better products than APHRO and GSMaP. On the other hand, simulated runoffs using GSMaP show large underestimations with observation in the three Rivers. As Getirana et al. (2011) pointed out in northern Amazon Basin, gauge-based precipitation products, such as K12, APHRO and GPCC, are still the more representative as actual precipitation than products using satellite measurements, such as GSMaP and GPCP, in the Chao Phraya Basin.

Figure 4 shows the difference between results using GPCC and other precipitation products in mean annual precipitation, simulated evapotranspiration, and simulated runoff from 1998 to 2006. Cold and warm colors mean results using GPCC are lower and higher than results using other products. Large differences in precipitation are shown in Figure 4a-1 (between GPCC and APHRO) in Myanmar, Malay Peninsula, and Sumatra Islands. Within most of the Southeast Asian region, APHRO precipitation is always lower than GPCC, despite both of them being gauge-based products. Yatagai et al. (2012) reported that the underestimation may be caused by the quality control system and different interpolation methods. However the authors could not determine the reason why APHRO precipitation is always lower the GPCC in the region, because the authors did not obtain details regarding the quality control systems, interpolation methods and data used for those products. GSMaP also has lower precipitation than GPCC over the region, but the differences in precipitation between GSMaP and GPCC are quite larger than between APHRO and GPCC. GPCP has higher precipitation in north Thailand, Cambodia, north Vietnam and middle Myanmar than GPCC, while it has lower precipitation in north, west and south Myanmar. The boundaries between warm and cold colors in Figure 4a2 are along the high mountain chains. As Biemans et al. (2009) mentioned, GPCC, APHRO and GPCP have similar monthly precipitation patterns (Figure 2a-1 and 2a-2). However, this study indicates low correlations in Myanmar and Sumatra Island where few gauging stations were used for APHRO and GPCC. Those regions have large differences also in precipitation amount (Figure $4 a-1$ and $4 a-2$ ). It can be said that uncertainties in seasonal and annual precipitation are large in Southeast Asia in regions where few gauging stations were used for the precipitation products.

Although precipitation has large difference (Figure 4a-1 and $4 \mathrm{a}-2$ ), simulated evapotranspiration has small difference

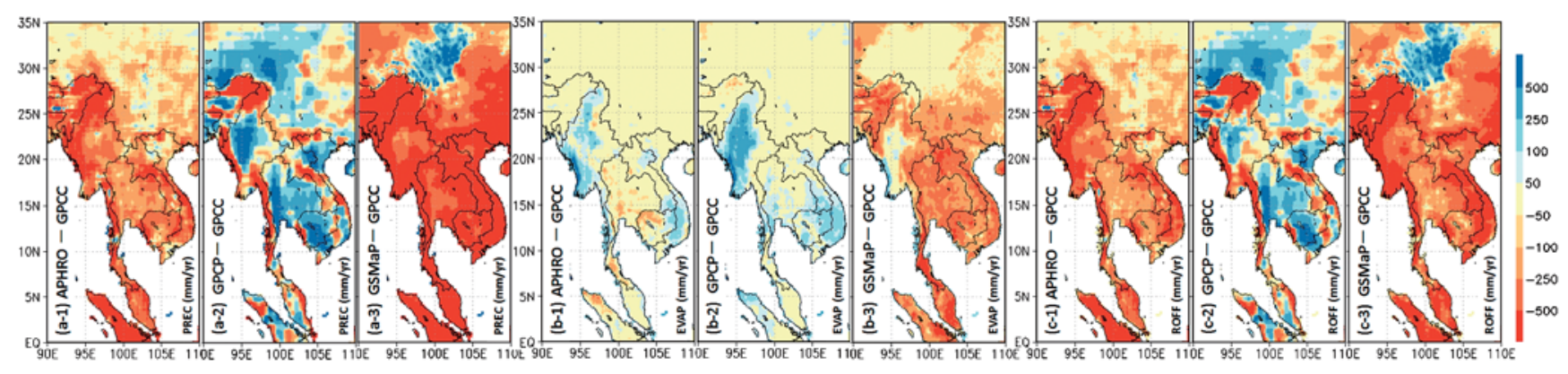

Figure 4. Difference in mean annual precipitation (a-1, a-2, a-3), simulated evapotranspiration (b-1, b-2, b-3), and simulated runoff (c-1, c-2, c-3) from 1998 to 2006. Units of every figure are $\mathrm{mm} \mathrm{yr}^{-1}$. The results using APHRODITE minus that of GPCC are shown in $\mathrm{a}-1, \mathrm{~b}-1, \mathrm{c}-1$. The results using GPCP minus that of GPCC are shown in a-2, b-2, c-2. The results using GSMaP minus that of GPCC are shown in a-3, b-3, c-3. Warm color indicates that precipitation, evapotranspiration, and runoff using GPCC are higher than other precipitation products 
(Figure 4b-1 and 4b-2). Most of the difference in precipitation translates to difference in runoff in Southeast Asia (Figure 4c-1 and 4c-2). Supplement Figure S2 shows the mean annual precipitation, simulated evapotranspiration, simulated runoff, and runoff ratios in the three basins averaged from 1998 to 2006. Red, blue, green, purple, orange, and black bars represent K12, GPCC, APHRO, GPCP, GSMaP, and observed discharge, respectively. Here, the runoff ratio is annual runoff divided by annual precipitation. Although both GPCC and APHRO are gaugebased products, projections using GPCC exceed APHRO by more than $200 \mathrm{~mm}$ in the three basins (Supplement Figure S2a). Although the amount of precipitation differs by more than $200 \mathrm{~mm}$ between the GPCC and APHRO simulations, the difference in simulated evapotranspiration is small in the three basins (Supplement Figure S2b). Since most of the difference in precipitation translates to difference in runoff in wet region as pointed out by Fekete and Vorosmarty (2004), small errors in precipitation can easily result in large errors in runoff in Southeast Asia. Additionally, Figure S2b demonstrates that percentage differences between simulated runoff using different gauged precipitation products are large in the Chao Phraya Basin compared to the Mekong and Irrawaddy Basins. Relatively low precipitation and runoff ratio cause a large percentage difference. Here, amount difference (e.g. $100 \mathrm{~mm}$ ) and percentage difference (e.g. $10 \%)$ are distinguished. If precipitation and runoff ratio is low, a small increase in precipitation causes a smaller increase in runoff in amount. The percentage increase of runoff and increase of runoff volume is different. Hence, small errors in precipitation can produce large percentage runoff errors in the Chao Phraya Basin. Supplement Figure S2c indicates that more than $80 \%$ of precipitation was lost through evapotranspiration in the Chao Phraya Basin. Supplement Table SIIa and SIIb also show a $4 \%$ overestimation of GPCC precipitation resulted in a 37\% overestimation in runoff under low runoff ratio conditions in the Chao Phraya Basin.

Figure 5 shows simulated runoff ratios from 1998 to 2006 using GPCC, APHRO, GPCP, and GSMaP. The results using GPCC (Figure 5a) clearly demonstrates that the runoff ratio in the Chao Phraya Basin is lower than other Southeast Asian basins. The low runoff ratio in the Chao Phraya River result from two main factors: mild slope of the basin as shown in Figure 1a and relatively lower precipitation than

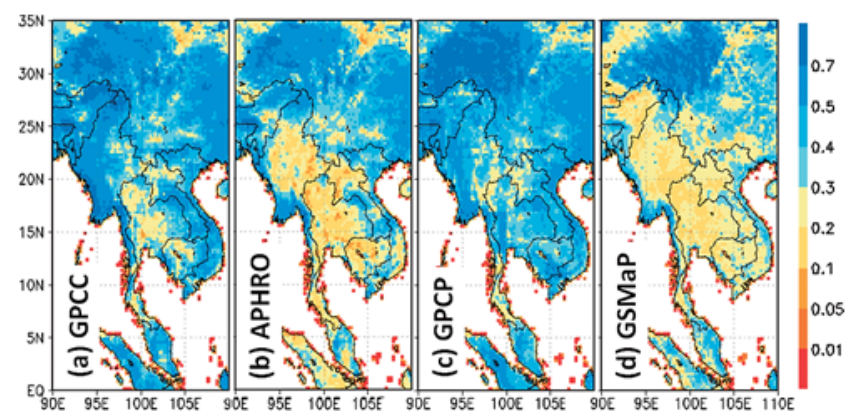

Figure 5. Simulated runoff ratios from 1998 to 2006 using (a) GPCC, (b) APHRODITE, (c) GPCP, and (d) GSMaP_MWR other Southeast Asian basins as shown in Supplement Figure $1 \mathrm{a}$.

Finally, uncertainties of precipitation products and their impacts on runoff estimates in the three basins can be summarized as follows. In the Chao Phraya Basin, although gauged precipitation products are similar, percentage differences between simulated runoff using different gauged precipitation products are large due to the relatively low precipitation and runoff ratio. In the Irrawaddy Basin, differences among gauged precipitation products are large. Because of relatively high precipitation and runoff ratio, the large differences in precipitation directly cause large differences in simulated runoff volume. In the Mekong Basin, gauged precipitation products are similar and runoff ratio is high. Hence, differences in simulated runoff volume are smaller than the Irrawaddy Basin, and percentage differences in simulated runoff are smaller than the Chao Phraya Basin. Although all three basins are located in wet Southeast Asia, impacts of precipitation errors on runoff estimates are different depending on precipitation amount and runoff ratio.

\section{CONCLUSIONS}

In this study, the authors conducted a comparative study of precipitation products through hydrological land surface simulation using the SiBUC. Through comparing precipitation products and performing long-term hydrological simulations over Southeast Asia using the products, the authors have reached the following main conclusions:

1) In the Chao Phraya Basin, gauge-based precipitation products are still the more representative as actual precipitation than products using satellite measurement. Since most of the difference in precipitation translates to difference in runoff in wet region, small errors in precipitation can easily result in large errors in runoff in Southeast Asia.

2) In Southeast Asia, gauge-based precipitation products have similar monthly precipitation patterns except for Myanmar and Sumatra Island where few gauging stations were used for the precipitation products. Myanmar and Sumatra Island have large differences also in precipitation amount. The uncertainties in seasonal and annual precipitation are large in Southeast Asia where few gauging stations were used for the precipitation products.

3) Even if located in wet Southeast Asia, impacts of precipitation errors on runoff estimates are different depending on precipitation amount and runoff ratio. Relatively low precipitation and runoff ratio cause large percentage differences in simulated runoff, as shown in the Chao Phraya Basin. Relatively high precipitation and runoff ratio cause a large difference in simulated runoff volume, as shown in Irrawaddy Basin.

In recent years, climate change has been causing serious issues relating to flood control and water resources management. This study implies that Southeast Asia has the potential to have large increases in runoff volume with small increases in precipitation under future climate. Especially, runoff in the Chao Phraya Basin is quite sensitive to an increase in precipitation because of the low runoff ratio. Climate change assessments will be necessary for water 
resources management in the future.

This study indicates uncertainties in seasonal and annual precipitation are large when gauging stations are insufficient in Southeast Asia. Although GSMaP showed poor performance in the Chao Phraya Basin, satellite-based products are quite important for such ungagged basins. Future spatial missions such as Global Precipitation Measurement (GPM) are desired to produce new satellitebased products for hydrological studies.

\section{ACKNOWLEDGEMENTS}

The authors wish to thank the Royal Irrigation Department of Thailand, the Electricity Generating Authority of Thailand, and the Thai Meteorological Department for providing their data sets. This work has been supported by a research project of the JICA entitled "Integrated Study on Hydro-Meteorological Prediction and Adaptation to Climate change in Thailand (IMPAC-T)" and the Japan Society for the Promotion of Science (JSPS).

\section{SUPPLEMENTS}

Figure S1. Mean annual precipitation (mm yr-1) from (a-1) GPCC, (a-2) APHRODITE, (a-3) GPCP, and (a-4) GSMaP_MWR from 1998 to 2006. Figure (b) shows river networks in Southeast Asia generated by an upscaling algorithm. The red circles are gauging stations for river discharge.

Figure S2. Mean annual (a) precipitation, (b) simulated evapotranspiration, (c) simulated runoff (bars), and runoff ratios (triangles) in the three basins averaged from 1998 to 2006. Red, blue, green, purple, orange, and black bars represent gauged precipitation (K12), GPCC, APHRODITE, GPCP, GSMaP_MWR, and observed discharge, respectively.

Table SI. Spatial resolutions of the products and their rain gauging stations in Chao Phraya (CP), Mekong (MK), and Irrawaddy (IR) Rivers.

Table SII. Calculated mean relative errors (MRE) and balance errors (BAL) at stations in the upper basin of the three rivers. Precipitation errors were calculated between data using gauged precipitation (K12) and four products. Runoff errors were calculated between simulated runoff using five sets of precipitation data and the observed discharge provided by RID and GRDC. Green, blue and gray colors represent very good, good, and poor agreement with observed data, respectively.

\section{REFERENCES}

Biemans H, Hutjes RW, Kabat P, Strengers BJ, Gerten D, Rost S. 2009. Effects of precipitation uncertainty on discharge calculation for main river basins. Journal of Hydrometeorol- ogy 10: 1011-1025. doi: 10.1175/2008JHM1067.1.

Fekete BM, Vorosmarty CJ. 2004. Uncertainties in precipitation and their impacts on runoff estimates. Journal of Climate 17: 294-304. doi: 10.1175/1520-0442(2004)017<0294:UIPATI> 2.0.CO;2.

GAME-T2 Data Center. 2005. http://hydro.iis.u-tokyo.ac.jp/ GAME-T/GAIN-T/index.html. Last access March 20, 2013

Getirana ACV, Espinoza JCV, Ronchail J, Filho OCR. 2011. Assessment of different precipitation data sets and their impacts on the water balance of the Negro basin. Journal of Hydrology 404: 304-322. doi: 10.1016/j.jhydrol.2011.04.037.

Hirabayashi Y, Kanae S, Motoya K, Masuda K, Doll P. 2008. A 59-year (1948-2006) global near-surface meteorological data set for land surface models. Hydrological Research Letters 2: 36-40. doi: 10.3178/hrl.2.36.

Huffman GJ, Bolvin DT. 2013. Version 1.2 GPCP One-Degree Daily Precipitation Data Set Documentation. http:// precip.gsfc.nasa.gov. Last access March 20, 2013.

Onogi K, Tsutsui J, Koide H, Sakamoto M, Kobayashi S, Hatsushika H, Matsumoto T, Yamazaki N, Kamahori H, Takahashi K, Kadokura S, Wada K, Kato K, Oyama R, Ose T, Mannoji N, Taira R. 2007. The JRA-25 reanalysis. Journal of the Meteorological Society of Japan 85: 369-432. doi: 10.2151/jmsj.85.369.

Portmann FT, Siebert S, Doll P. 2010. MIRCA2000 - Global monthly irrigated and rainfed crop areas around the year 2000: A new high-resolution data set for agricultural and hydrological modeling. Global Biogeochemical Cycles 24: 1-24. doi: 10.1029/2008GB003435.

Rudolf B, Andreas B, Udo S, Anja MC, Markus Z. 2010. GPCC status Report December 2010. http://gpcc.dwd.de. Last access March 20, 2013.

Sellers PJ, Mintz Y, Sud YC, Dalcher A. 1986. A simple biosphere model $(\mathrm{SiB})$ for use within general circulation models. Journal of the Atmospheric Sciences 43: 505-531. doi: 10.1175/1520-0469(1986)043<0505:ASBMFU>2.0.CO;2.

Tanaka K. 2004. Development of the New Land Surface Scheme SiBUC Commonly Applicable to Basin Water Management and Numerical Weather Prediction Model. Doctoral Dissertation, Graduate School of Engineering, Kyoto University: Kyoto; 289.

The World Bank. 2012. Thai Flood 2011: Rapid Assessment for resilient recoverly and reconstruction planning. https:// www.gfdrr.org/thaifloods2012. Last access April 10, 2013.

Ushio T, Sasashige K, Kubota T, Shige S, Okamoto K, Aonashi K, Inoue T, Takanashi N, Iguchi T, Kachi M, Oki R, Morimoto T, Kawasaki Z. 2009. A Kalman filter approach to the Global Satellite Mapping of Precipitation (GSMaP) from combined passive microwave and infrared radiometric data. Journal of the Meteorological Society of Japan 87A: 137-151. doi: 10.2151/jmsj.87A.137.

Yamazaki D, Oki T, Kanae S. 2009. Deriving a global river network map and sub-grid topographic characteristics from a fineresolution flow direction map. Hydrology and Earth System Sciences 13: 2241-2251. doi: 10.5194/hess-13-2241-2009.

Yatagai A, Kamiguchi K, Arakawa O, Hamada A, Yasutomi N, Kitoh A. 2012. APHRODITE: Constructing a Long-term Daily Gridded Precipitation Dataset for Asia based on a Dense Network of Rain Gauges. Bulletin of American Meteorological Society 93: 1401-1415. doi: 10.1175/BAMS-D-1100122.1. 